\title{
The role of mannose-binding lectin in pneumococcal infection
}

\author{
M. Isabel García-Laorden, Felipe Rodríguez de Castro, Jordi Solé-Violán, \\ Antoni Payeras, M. Luisa Briones, Luis Borderías, Javier Aspa, José Blanquer, \\ Olga Rajas, J. Alberto Marcos-Ramos, Estefanía Herrera-Ramos, \\ Miguel A. García-Bello, Judith Noda, José M. Ferrer, \\ Jordi Rello and Carlos Rodríguez-Gallego
}

ABSTRACT: The role of mannose-binding lectin (MBL) deficiency (MBL2; XA/O and O/O genotypes) in host defences remains controversial. The surfactant proteins (SP)-A1, -A2 and -D, other collectins whose genes are located near MBL2, are part of the first-line lung defence against infection. We analysed the role of MBL on susceptibility to pneumococcal infection and the existence of linkage disequilibrium (LD) among the four genes.

We studied 348 patients with pneumococcal community-acquired pneumonia (P-CAP) and 2,110 controls. A meta-analysis of MBL2 genotypes in susceptibility to P-CAP and to invasive pneumococcal disease (IPD) was also performed. The extent of LD of MBL2 with SFTPA1, SFTPA2 and SFTPD was analysed.

MBL2 genotypes did not associate with either P-CAP or bacteraemic P-CAP in the case-control study. The MBL-deficient $O / O$ genotype was significantly associated with higher risk of IPD in a meta-analysis, whereas the other MBL-deficient genotype (XA/O) showed a trend towards a protective role. We showed the existence of LD between MBL2 and SP genes.

The data do not support a role of MBL deficiency on susceptibility to P-CAP or to IPD. LD among MBL2 and SP genes must be considered in studies on the role of MBL in infectious diseases.

KEYWORDS: Mannose-binding lectin, pneumococcus, polymorphism, sepsis, Streptococcus pneumoniae, surfactant protein

ommunity-acquired pneumonia (CAP) remains the leading cause of death from infection in developed countries [1]. Several microorganisms may be causative agents of CAP, but Streptococcus pneumoniae is the most common cause [1].

Mannose-binding lectin (MBL) is a serum collectin that promotes phagocytosis of microorganisms and initiates the lectin pathway of complement activation [2]. Deficient and low MBL serum levels are mainly due to the presence of three common point mutations in the exon 1 of the MBL2 gene (10q11.2-q21): alleles $B, C$ and $D$ are termed $O$ alleles, and $A$ is the wild-type allele. Heterozygous individuals for $O$ alleles have reduced serum MBL levels and MBL-dependent lectin pathway activity, whereas these values are very low or absent in homozygous individuals for $O$ alleles. The presence of the promoter allele $X$ has an important downregulating effect, and
$O / O$ together with $X A / O$ genotypes are considered MBL deficient genotypes, which are common in most populations $[2,3]$.

MBL deficiency has been considered a common primary immunodeficiency [4]. However, its role in host defence remains a matter of debate $[5,6]$. An initial study suggested that $O / O$ genotypes predispose to invasive pneumococcal disease (IPD) [7], but these results were not replicated in two other populations [8,9]. The data from several studies argue against a role of MBL in host defences, particularly to pneumococcus [5, 10-13]. We have previously observed that MBL plays a redundant role in human defences against primary infection, at least in adults with $\mathrm{CAP}$, but also that MBL insufficiency predisposes to higher severity and fatal outcome in CAP [14]. Surfactant proteins (SP)-A1, -A2 and -D, and other collectins, also promote phagocytosis of microorganisms and play a pivotal role in the

This article has supplementary material available from www.erj.ersjournals.com

AFFILIATIONS

For the authors' affiliations, see the Acknowledgements section

CORRESPONDENCE

C. Rodríguez-Gallego Servicio de Inmunología Hospital Universitario de Gran Canaria Dr Negrín Barranco de la Ballena s/n 35010 Las Palmas de Gran Canaria Spain

E-mail: jrodgal@

gobiernodecanarias.org

Received:

Oct 072011

Accepted:

Mar 272012

First published online:

Apr 202012 
regulation of the inflammatory response, as well as in clearance of apoptotic cells $[15,16]$. SPs, but not MBL, take part in the first-line host defence in healthy lung. Genetic variability at genes coding for these SPs was associated with higher susceptibility and poor outcome of CAP [17]. The human SP-A locus consists of two similar genes, SFTPA1 and SFTPA2, localised within a cluster (10q21-24) that includes the SP-D gene (SFTPD) [15]. MBL2 was reported not to be in physical linkage with the genes of these SPs [18], but no studies of linkage disequilibrium (LD) of MBL2 with SFTPA1, SFTPA2 or SFTPD have been performed to date.

In the present study, we assessed the role of MBL2 genotypes in the susceptibility to and the severity of pneumococcal CAP (P-CAP). We also performed a meta-analysis aimed to analyse the role of MBL2 genotypes in susceptibility to P-CAP and to IPD. Lastly, we analysed the extent of LD of the most frequently studied single nucleotide polymorphisms (SNPs) of MBL2 with missense SNPs at SFTPA1, SFTPA2 and SFTPD.

\begin{tabular}{|c|c|c|c|}
\hline TABLE 1 & \multicolumn{3}{|c|}{$\begin{array}{l}\text { Demographic and clinical characteristics of } \\
\text { pneumococcal community-acquired pneumonia } \\
\text { patients }\end{array}$} \\
\hline \multicolumn{2}{|c|}{ Characteristics $^{\#}$} & Available data & Subjects \\
\hline \multicolumn{2}{|l|}{ Age yrs } & 348 & $59.50 \pm 17.62$ \\
\hline \multicolumn{2}{|l|}{ Sex } & 348 & \\
\hline \multicolumn{2}{|l|}{ Male } & & 227 (65.2) \\
\hline \multicolumn{2}{|l|}{ Female } & & $121(34.8)$ \\
\hline \multicolumn{2}{|c|}{ ICU admission } & 348 & $133(38.2)$ \\
\hline \multicolumn{2}{|l|}{ MODS } & 348 & $74(21.3)$ \\
\hline \multicolumn{2}{|l|}{ ARDS } & 348 & $26(7.5)$ \\
\hline \multicolumn{2}{|c|}{ Septic shock } & 348 & 79 (22.7) \\
\hline \multicolumn{2}{|l|}{ ARF } & 348 & $250(71.8)$ \\
\hline \multicolumn{2}{|c|}{ Acute renal failure } & 346 & $114(32.9)$ \\
\hline \multicolumn{2}{|c|}{ Bacteraemia } & 347 & $96(27.7)$ \\
\hline \multicolumn{2}{|c|}{ 90-day exitus } & 348 & $23(6.6)$ \\
\hline \multicolumn{2}{|c|}{ 28-day exitus } & 348 & $16(4.6)$ \\
\hline \multicolumn{4}{|c|}{ Comorbidity ${ }^{\#}$} \\
\hline \multicolumn{2}{|c|}{ No } & 338 & $122(36.1)$ \\
\hline \multicolumn{2}{|l|}{ COPD } & 343 & $86(25.1)$ \\
\hline \multicolumn{2}{|l|}{ Asthma } & 322 & $13(4.0)$ \\
\hline \multicolumn{2}{|l|}{ Neoplasy } & 344 & $35(10.2)$ \\
\hline \multicolumn{2}{|c|}{ Ischaemic cardiopathy } & 343 & $30(8.8)$ \\
\hline \multicolumn{2}{|l|}{ Diabetes } & 343 & $76(22.2)$ \\
\hline \multicolumn{2}{|c|}{ Renal insufficiency } & 322 & $13(4.0)$ \\
\hline \multicolumn{2}{|c|}{ Hepatic insufficiency } & 343 & $31(9.0)$ \\
\hline \multicolumn{2}{|c|}{ Neurological pathology } & 343 & $38(11.1)$ \\
\hline \multicolumn{2}{|c|}{ Autoimmune pathology } & 343 & $7(2.1)$ \\
\hline \multicolumn{2}{|c|}{ Pneumonia severity index } & 335 & \\
\hline \multicolumn{2}{|l|}{ I-III (low) } & & $148(44.2)$ \\
\hline \multicolumn{2}{|c|}{ IV-V (moderate-high) } & & $187(55.8)$ \\
\hline
\end{tabular}

Data are presented as $n$, mean \pm SD or $n(\%)$. ICU: intensive care unit; MODS: multi-organ dysfunction syndrome; ARDS: acute respiratory distress syndrome; ARF: acute respiratory failure; COPD: chronic obstructive pulmonary disease. $\#:$ some patients had more than one comorbidity.

\section{METHODS}

\section{Patients and controls}

In the present study, 1,398 white Spanish patients hospitalised with CAP (59.50 \pm 17.62 yrs, 34.8\% females) from five Spanish hospitals (Hospital Universitario de Gran Canaria Doctor Negrín, Las Palmas de Gran Canaria; Hospital Clínico y Universitario de Valencia, Valencia; Hospital San Jorge de Huesca, Huesca; Hospital Universitario de la Princesa, Madrid; and Hospital Vall DHebron, Barcelona), were prospectively included. A total of 348 patients had P-CAP. The control group consisted of 2,110 unrelated healthy volunteers (blood and bone marrow donors as well as hospital staff) and patients without signs of relevant infectious diseases $(47.27 \pm 17.40 \mathrm{yrs}$, $48.2 \%$ females) from the same origin as CAP patients. Foreigners and individuals with ancestors other than Spanish were previously excluded. Exclusion criteria and clinical definitions are shown in the Methods section of the online supplementary material. For susceptibility to P-CAP, a sexand age-matched case-control study was performed; 340 patients and 1,736 controls were finally compared. Severity and outcome were evaluated in a prospective study of the 348 P-CAP patients.

In addition, we included a group of 84 patients with P-CAP $(62.00 \pm 16.53 \mathrm{yrs}, 32.1 \%$ females $)$ from another Spanish population. These patients were included in a published study [19], but several patients were excluded on the basis of our inclusion/ exclusion criteria. A group of 91 healthy controls from the same origin were also used $(64.95 \pm 18.61 \mathrm{yrs}, 72.5 \%$ females $)$.

Informed consent was obtained from either the patients or their relatives. The protocol was approved by the local ethics committee of all hospitals. All steps were performed in complete accordance to the Helsinki declaration.

\section{Genotyping}

Genomic DNA was isolated as previously described [17]. The following $M B L 2$ polymorphisms were analysed as described elsewhere [20]: codon $52 \mathrm{C} / \mathrm{T}$ (rs5030737, allele $D)$, codon $54 \mathrm{~A} / \mathrm{G}$ (rs1800450, allele $B$ ), codon 57 A/G (rs1800451, allele C) and codon -221 G/C (rs7096206, alleles X/Y). Haplotypes were simplified as $Y A, X A$ and $O$.

We have previously genotyped polymorphisms in SFTPA1 (aa19 T/C, rs1059047; aa50 G/C, rs1136450; aa219 C/T, 4253527), SFTPA2 (aa9 A/C, rs1059046; aa91 G/C, rs17886395; aa223 C/A, rs4253527) and SFTPD (aa11 T/C, rs721917) genes in part of both patient and control groups [17]. Haplotypes were named as $6 A^{n}$ for SFTPA1 and $1 A^{n}$ for SFTPA2 based on previous nomenclature [21]. For each individual, haplotypes were inferred using PHASE statistical software (version 2.1; available at www.stat.washington.edu/stephens/phase).

LD was measured by means of Arlequin (version 3.11; available at http://cmpg.unibe.ch/software/arlequin3) and Haploview (version 4.2; available at www.broadinstitute.org/ haploview /haploview) softwares. Pairwise LD between MBL2 haplotypes and SP genes was characterised using Arlequin 3.11. The existence of LD was considered if $\mathrm{D}^{\prime}>0.3$.

\section{Study selection for the meta-analysis}

Eligible studies were identified by searching in PubMed using the search terms "mannose-binding lectin" or "mannose 


\begin{tabular}{|c|c|c|c|c|c|c|c|c|}
\hline \multirow{2}{*}{ TABLE 2} & \multicolumn{8}{|c|}{ Genotypes } \\
\hline & YA/YA & $X A / Y A$ & $X A / X A$ & $Y A / O$ & $X A / O$ & $0 / 0$ & $X A / O+O / O$ & $A / O+O / O$ \\
\hline Controls ${ }^{\#}$ & $558(32.1)$ & $412(23.7)$ & $62(3.6)$ & $443(25.5)$ & $172(9.9)$ & $89(5.1)$ & $261(15.0)$ & $705(40.6)$ \\
\hline $\mathrm{ICU}$ & $46(34.6)$ & 26 (19.5) & $3(2.3)$ & $35(26.3)$ & $15(11.3)$ & $8(6.0)$ & $23(17.3)$ & $58(43.6)$ \\
\hline General ward & $90(41.9)$ & $38(17.7)$ & $12(5.6)$ & $54(25.1)$ & $13(6.0)$ & $8(3.7)$ & $21(9.8)$ & $75(34.9)$ \\
\hline Bacteraemia & $34(35.4)$ & $20(20.8)$ & $4(4.2)$ & $26(27.1)$ & $7(7.3)$ & $5(5.2)$ & $12(12.5)$ & 38 (39.6) \\
\hline No bacteraemia & $102(40.6)$ & $44(17.5)$ & $11(4.4)$ & $62(24.7)$ & $21(8.4)$ & $11(4.4)$ & $32(12.7)$ & $94(37.5)$ \\
\hline Acute renal failure & $38(33.3)$ & $22(19.3)$ & $2(1.8)$ & $36(31.6)$ & $10(8.8)$ & $6(5.3)$ & $16(14.0)$ & $52(45.6)$ \\
\hline No acute renal failure & $98(42.2)$ & $42(18.1)$ & $13(5.6)$ & $52(22.4)$ & $17(7.3)$ & $10(4.3)$ & 27 (11.6) & $79(34.1)$ \\
\hline ARF & $97(38.8)$ & $48(19.2)$ & $4(1.6)$ & $64(25.6)$ & $24(9.6)$ & $13(5.2)$ & $37(14.8)$ & $101(40.4)$ \\
\hline No ARF & $39(39.8)$ & $16(16.3)$ & $11(11.2)$ & $25(25.5)$ & $4(4.1)$ & $3(3.1)$ & $7(7.1)$ & $32(32.7)$ \\
\hline ARDS & $8(30.8)$ & $7(26.9)$ & $1(3.8)$ & $4(15.4)$ & $5(19.2)$ & 1 (3.8) & $6(23.1)$ & $10(38.5)$ \\
\hline No ARDS & 128 (39.8) & $57(17.7)$ & $14(4.3)$ & 85 (26.4) & $23(7.1)$ & $15(4.7)$ & 38 (11.8) & $123(38.2)$ \\
\hline MODS & $18(24.3)$ & $15(20.3)$ & $2(2.7)$ & $24(32.4)$ & $10(13.5)$ & $5(6.8)$ & 15 (20.3) & $39(52.7)$ \\
\hline No MODS & $118(43.1)$ & 49 (17.9) & $13(4.7)$ & 65 (23.7) & $18(6.6)$ & $11(4.0)$ & 29 (10.6) & $94(34.3)$ \\
\hline PSI I-III & $60(40.5)$ & 27 (18.2) & $12(8.1)$ & $37(25.0)$ & $8(5.4)$ & $4(2.7)$ & $12(8.1)$ & $49(33.1)$ \\
\hline PSI IV-V & 67 (35.8) & 35 (18.7) & $2(1.1)$ & $51(27.3)$ & $20(10.7)$ & $12(6.4)$ & 32 (17.1) & $83(44.4)$ \\
\hline
\end{tabular}

Data are presented as $n$ (\%). For susceptibility analysis, only sex- and age-matched P-CAP patients and controls are included. ICU: intensive care unit; SSh: septic shock; SS: severe sepsis; NSS: non-severe sepsis, includes patients without either severe sepsis or septic shock; ARF: acute respiratory failure; ARDS: acute respiratory distress syndrome; MODS: multi-organ dysfunction syndrome; PSI: pneumonia severity index. ${ }^{\#}: n=1736 ;{ }^{\bullet}: n=340 ;{ }^{+}: n=348$.

binding protein" and "pneumococcal" or "pneumonia", and abstracts and references were reviewed for relevance. Full text of the relevant articles was reviewed to ensure that they met pre-set inclusion criteria. Data were extracted independently by two investigators, and the duplicate results were compared.

We identified 93 publications related to MBL and pneumonia or pneumococcus. After reviewing, 89 articles were excluded because they were reviews, met our exclusion criteria, or because they provided only serum data, data from patients with or without pneumococcus could not be separated, or they were irrelevant to the focus of this meta-analysis. Four studies remained after the selection process [7-9, 22]. Studies were separated into those focused on P-CAP or IPD. Three genotypes were studied in our meta-analysis: $\mathrm{O} / \mathrm{O}, \mathrm{A} / \mathrm{O}+\mathrm{O} / \mathrm{O}$ and $X A / O$.

\section{Statistical analysis}

Quantitative variables are presented using arithmetic mean \pm SEM. The comparison of MBL2 genotypes distribution based on the susceptibility, severity and outcome were performed using the Chi-squared test or Fisher's exact test when needed, and odds ratios with $95 \%$ of confidence intervals were calculated. In addition, for the study of susceptibility, cases and controls were sex- and age-matched (considering intervals of $5 \mathrm{yrs}$ ), and the strata created were used for the conditional logistic regression analysis. The relationship between severity or outcome and genotypes was evaluated by binary logistic regression models, and hospital of origin and pneumonia severity index (PSI) were included as independent variables. The Hardy-Weinberg equilibrium for the genotypic frequencies was tested in the control groups by Chi-squared analysis. Assuming a frequency in our population of 0.15 for $\mathrm{X} / \mathrm{O}+\mathrm{O} / \mathrm{O}$ genotypes, our study (1,591 controls, $348 \mathrm{P}$-CAP patients and 96 bacteraemic P-CAP patients; incidence for bacteraemia of 0.28 ) had $80 \%$ power to detect an odds ratio of 1.53 and 2.03 for susceptibility to P-CAP and bacteraemic P-CAP, respectively. All tests were two-tailed. Statistical significance was taken as $\mathrm{p}<0.05$. Statistical analysis was performed using SPSS 15.0 (SPSS Inc., Chicago, IL, USA). Metaanalyses were performed using DerSimonian and Laird random-effects models. For individual studies and pooled estimation, odds ratios and 95\% confidence intervals are given. Heterogeneity was evaluated and it is showed in the forest plot. Analysis was performed using the Metafor package (available at www.jstatsoft.org/v36/i03/).

\section{RESULTS}

Patients admitted at five Spanish Hospitals were evaluated for the diagnosis of CAP. After excluding those patients without informed consent, ethnicity other than white Spanish and those 
TABLE 3 Statistical analysis of the main differences of the observed genotypic frequencies from table 2

\begin{tabular}{|c|c|c|c|c|c|c|}
\hline & \multicolumn{6}{|c|}{ Genotypes } \\
\hline & YA/YA & $X A / Y A$ & $X A / X A$ & $X A / O$ & $X A / O+O / O$ & $\mathrm{~A} / \mathrm{O}+\mathrm{O} / \mathrm{O}$ \\
\hline P-CAP versus controls & $\begin{array}{c}1.43(1.11-1.84) ; \\
0.006\end{array}$ & $\begin{array}{c}0.62(0.47-0.87) \\
0.005\end{array}$ & & & & \\
\hline ICU versus general ward & & & & & $\begin{array}{c}1.93(1.02-3.65) \\
0.040\end{array}$ & \\
\hline SSh+SS versus NSS & & & $\begin{array}{c}0.19(0.04-0.85) \\
0.015\end{array}$ & & & $\begin{array}{c}1.55(1.00-2.40) \\
0.048\end{array}$ \\
\hline $\begin{array}{l}\text { Acute renal failure versus } \\
\text { no acute renal failure }\end{array}$ & & & & & & $\begin{array}{c}1.62(1.03-2.58) ; \\
0.037\end{array}$ \\
\hline ARF versus no ARF & & & $\begin{array}{c}0.43(0.24-0.76) \\
0.0003\end{array}$ & & & \\
\hline PSI IV-V versus I-III & & & $\begin{array}{c}0.12(0.03-0.56) \\
0.001\end{array}$ & & $\begin{array}{c}2.34(1.16-4.72) \\
0.015\end{array}$ & $\begin{array}{c}1.61(1.03-2.52) ; \\
0.036\end{array}$ \\
\hline
\end{tabular}

Data are presented as OR (95\% Cl); p-value. Values are uncorrected p-value for the bivariate comparison, except for the susceptibility analysis, where values correspond to conditional estimates. P-CAP: pneumococcal community-acquired pneumonia; ICU: intensive care unit; SSh: septic shock; SS: severe sepsis; NSS: non-severe sepsis, includes patients without either severe sepsis or septic shock; ARF: acute respiratory failure; MODS: multi-organ dysfunction syndrome; PSI: pneumonia severity index.

that fulfilled the exclusion criteria, a total of 1,398 CAP patients were finally studied. S. pneumoniae was detected in 348 $(24.89 \%)$ of these patients $(57.43 \%$ of the patients with known causative microorganism). The main clinical characteristics of the P-CAP patients are shown in table 1 .

\section{Susceptibility to P-CAP related to MBL2 genotypes}

No significant deviation from Hardy-Weinberg equilibrium of the studied MBL2 variants was found in our control population.

When $M B L 2$ genotypes encompassing exon 1 wild-type $(A)$ and mutated alleles $(O)$, as well as promoter $X / Y$ alleles, were analysed, no differences in $\mathrm{A} / \mathrm{O}+\mathrm{O} / \mathrm{O}$ or $\mathrm{X} A / \mathrm{O}+\mathrm{O} / \mathrm{O}$ genotypes between sex- and age-matched P-CAP patients and controls were observed. However, the high-MBL genotype $Y A / Y A$ was found to be over-represented in these patients, and genotype $X A / Y A$ was under-represented when compared with controls (tables 2 and 3).

\section{Severity and outcome of P-CAP patients related to MBL2 genotypes}

The relevance of MBL2 variants in the severity of P-CAP was analysed in our main cohort (tables 2 and 3). The high-MBL genotype $Y A Y Y A$ was under-represented in P-CAP patients with multi-organ dysfunctions (MODS). Likewise, the $X A / X A$ genotype was under-represented in P-CAP patients with the most severe forms of sepsis (septic shock (SSh) and severe sepsis), as well as in those with acute respiratory failure (ARF) or moderate-to-high PSI. Conversely, the frequency of $X A / O$ genotypes was found to be higher in P-CAP patients with SSh. In addition, when MBL-deficient genotypes $(\mathrm{X} A / \mathrm{O}+\mathrm{O} / \mathrm{O})$ were analysed, we found them to be associated with a need of intensive care unit admission, development of SSh and MODS; and with a moderate-to-high PSI at admission. Six of these associations remained significant in multivariate analysis including the variables hospital of origin and PSI (except for the analysis of the PSI, which only included hospital of origin): $\mathrm{p}=0.029$ (OR 0.49 , 95\% CI 0.26-0.93) for $Y A / Y A$ genotype in patients with MODS; $\mathrm{p}=0.005(\mathrm{OR}=0.12,95 \%$ CI $0.03-0.53)$ and $\mathrm{p}=0.005(\mathrm{OR}=0.11,95 \% \mathrm{CI} 0.02-0.52)$ for $X A / X A$ in patients with ARF and PSI IV-V, respectively; $\mathrm{p}=0.041$ $(\mathrm{OR}=2.43,95 \%$ CI $1.04-5.70)$ for $X A / O$ in patients with SSh; and $\mathrm{p}=0.019(\mathrm{OR}=2.37,95 \% \mathrm{CI} 1.16-4.88)$ and $\mathrm{p}=0.038$ $(\mathrm{OR}=1.63,95 \% \mathrm{CI} 1.03-2.58)$ in patients with PSI IV-V for $\mathrm{X} / \mathrm{O}+\mathrm{O} / \mathrm{O}$ and $\mathrm{A} / \mathrm{O}+\mathrm{O} / \mathrm{O}$ genotypes, respectively. No significant differences were observed when acute respiratory distress syndrome, bacteraemia and fatal outcome were analysed (data not shown).

\section{Data from another Spanish population}

We also analysed data from another Spanish population included in a previously published study [19]. A total of 84 P-CAP patients (51.19\% with bacteraemic P-CAP), and a group of 91 healthy controls were compared for MBL2 genotypes. This control population was in Hardy-Weinberg equilibrium. No relevant differences between patients and controls were observed. Data about severity were not available.

\section{Association between MBL2 and pneumococcal infection: meta-analysis}

The characteristics of previous studies included in our metaanalyses are shown in table 4 . The role of MBL2 genotypes on 
susceptibility to P-CAP was analysed in a meta-analysis including our two case-control studies and data from a previous study [22]. No differences of MBL2 genotypes between patients and controls were observed (fig. 1). There was no statistically significant heterogeneity among the included studies for any of the three meta-analysis.

Three previous studies analysed the role of $M B L 2$ genotypes in the susceptibility to IPD. RoY et al. [7] reported in two independent case-control studies that $\mathrm{O} / \mathrm{O}$ homozygous patients have an increased risk of IPD, but these results were not replicated in other populations $[8,9]$. Data from patients with bacteraemic P-CAP and healthy controls from our two case-control studies were independently included with those previous data in a meta-analysis. Figure 2 a shows the $O / O$ versus $A / A+A / O$ forest plot. This analysis showed that the MBLdeficient genotype $O / O$ was significantly associated with a risk of acquiring IPD ( $\mathrm{p}<0.0001$; pooled OR 2.16, 95\% CI 1.52-3.09). No significant associations were found for the $A O+O / O$ genotypes (fig. 2b). Nevertheless, the other MBL-deficient genotype, $X A / O$, showed a trend towards a protective role (pooled OR 0.73, 95\% CI 0.51-1.04) (fig. 2c). There was no statistically significant heterogeneity among the included studies for any of the three meta-analysis. As expected, when $\mathrm{X} / \mathrm{O}+\mathrm{O} / \mathrm{O}$ genotypes were analysed, no significant differences were found (data not shown).

\section{LD of MBL2, SFTPA1, SFTPA2 and SFTPD genes}

As we have previously shown in our population, there is LD among several SNPs at SFTPA1 and SFTPA2, whereas SFTPD aa11 was only observed in LD with SFTPA1 aa19 (fig. S1) [17]. As expected, pairwise $L D\left(D^{\prime}\right)$ confirmed the existence of a very strong LD within MBL2 SNPs. Several SNPs of SFTPA1 and SFTPA2, but not the SFTPD aa11 SNP, were found to be in LD with MBL2 SNPs (fig. S1). The value of LD measured as $r^{2}$ was very low for every pair of SNPs (data not shown), and none of the studied SNPs could be used as haplotype-tagging SNP to infer the observed haplotypes. In addition, when pairwise LD was measured among haplotypes instead of among SNPs; some haplotypes were found to be in LD with $M B L 2$ variants (table 5 ).

\section{Susceptibility to P-CAP related to haplotypes encompassing SFTPD, SFTPA1, SFTPA2 and MBL2}

We also intended to analyse whether phased variants encompassing the four genes were involved in susceptibility to PCAP. Due to the existence of LD, only 177 of the 2,048 expected haplotypes encompassing SFTPD, SFTPA1, SFTPA2 and MBL2 were observed, and only 18 had frequencies higher than $1 \%$ (data not shown). We previously reported a protective effect of the $6 A^{2}, 1 A^{0}, 6 A^{2}-1 A^{0}$ and $C-6 A^{2}-1 A^{0}$ haplotypes on susceptibility to CAP [17]. When susceptibility to P-CAP was studied in the present study, the protective effect of these haplotypes was even higher when they co-segregate with the MBL2 XA variant (table 6). However, these results did not remain significant after a conservative Bonferroni correction for the number of observed haplotypes.

\section{DISCUSSION}

Previous meta-analysis based on genetic association studies concluded that the MBL2 O/O genotype predisposes to infection by $S$. pneumoniae. We herein provide new data 
a)

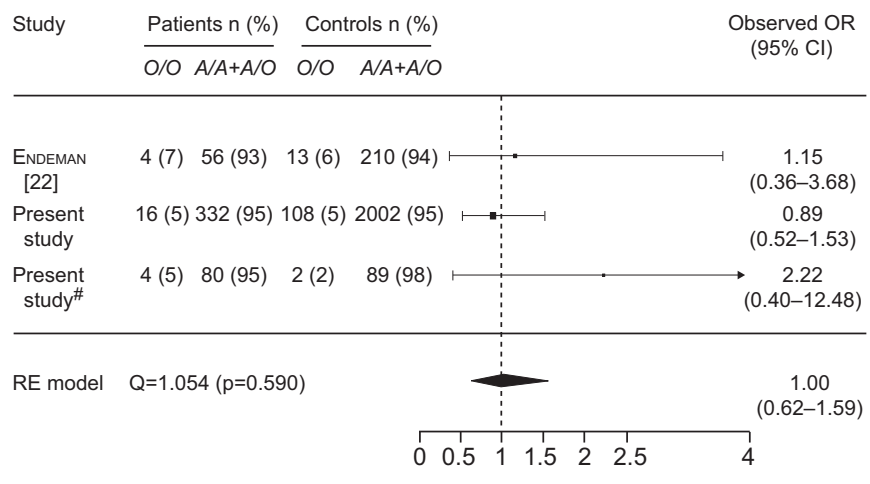

c)

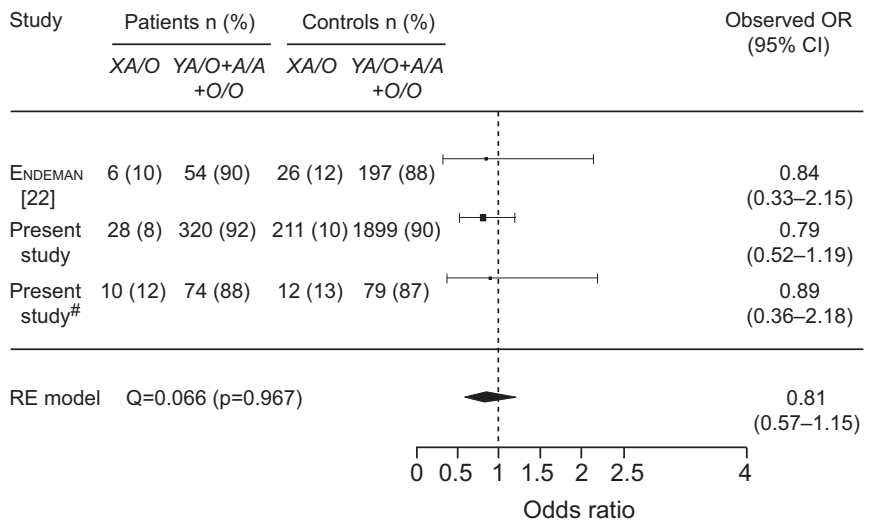

a)

\begin{tabular}{|c|c|c|c|c|c|c|c|c|}
\hline \multirow[t]{2}{*}{ Study } & \multicolumn{2}{|c|}{ Patients n (\%) } & \multicolumn{2}{|c|}{ Controls n (\%) } & & & & \multirow{2}{*}{$\begin{array}{l}\text { Observed } \\
\text { OR (95\% Cl) }\end{array}$} \\
\hline & $\mathrm{O} / \mathrm{O}$ & $A / A+A / O$ & $\mathrm{O} / \mathrm{O}$ & $A / A+A / C$ & & & & \\
\hline $\begin{array}{l}\text { KRONBORG } \\
{[9]}\end{array}$ & $9(6)$ & $131(94)$ & 7 (3) & $243(97)$ & & & & $\rightarrow \begin{array}{c}2.38 \\
(0.87-6.55)\end{array}$ \\
\hline $\operatorname{Ror}[7]^{\#}$ & $28(12)$ & $201(88)$ & $18(5)$ & $335(95)$ & & & & $\rightarrow \begin{array}{c}2.59 \\
(1.40-4.81)\end{array}$ \\
\hline $\operatorname{Ror}[7]^{\pi}$ & $11(10)$ & $97(90)$ & $36(5)$ & $643(95)$ & & & & $\begin{array}{c}2.03 \\
(1.00-4.11)\end{array}$ \\
\hline $\begin{array}{l}\text { MOENS } \\
{[8]}\end{array}$ & $7(11)$ & $56(89)$ & $7(4)$ & $155(96)$ & & & & $\rightarrow \begin{array}{c}2.77 \\
(0.93-8.24)\end{array}$ \\
\hline $\begin{array}{l}\text { Present } \\
\text { study }\end{array}$ & $5(5)$ & $92(95)$ & $108(5)$ & $2002(95$ & & & & $\begin{array}{c}1.02 \\
(0.41-2.56)\end{array}$ \\
\hline $\begin{array}{l}\text { Present } \\
\text { study }^{+}\end{array}$ & $4(9)$ & $39(91)$ & $2(2)$ & $89(98)$ & & & & $\begin{array}{c}4.56 \\
\rightarrow(0.80-25.97)\end{array}$ \\
\hline \multirow[t]{2}{*}{ RE model } & \multirow{2}{*}{\multicolumn{2}{|c|}{$\mathrm{Q}=3.871(\mathrm{p}=0.5$}} & $.568)$ & & & & \multirow{2}{*}{\multicolumn{2}{|c|}{$\begin{array}{c}2.16 \\
(1.52-3.09)\end{array}$}} \\
\hline & & & & 0 & 0.5 & $\begin{array}{lllll} & 1 & 1 & 1 & 1 \\
1 & 2 & 2.5\end{array}$ & & \\
\hline c) & & & & & & Odds ratio & & \\
\hline \multirow[t]{2}{*}{ Study } & \multicolumn{2}{|c|}{ Patients n (\%) } & \multicolumn{2}{|c|}{ Controls n (\%) } & & & \multirow{2}{*}{\multicolumn{2}{|c|}{$\begin{array}{l}\text { Observed } \\
\text { OR }(95 \% \mathrm{Cl})\end{array}$}} \\
\hline & \multicolumn{2}{|c|}{$\begin{array}{c}X A / O Y A / O+A / A \\
+O / O \\
\end{array}$} & \multicolumn{2}{|c|}{$\begin{array}{c}\overline{X A / O Y A / O+A / A} \\
+O / O \\
\end{array}$} & & & & \\
\hline \multirow{2}{*}{$\begin{array}{l}\text { KRONBORG } \\
{[9]} \\
\text { RoY }[7]^{\#}\end{array}$} & $11(8)$ & $129(92)$ & $33(13)$ & $217(87)$ & & -1 & \multicolumn{2}{|r|}{$\begin{array}{c}0.56 \\
(0.27-1.15)\end{array}$} \\
\hline & $21(9)$ & $208(91)$ & $32(9)$ & $321(91)$ & & & & $\begin{array}{c}1.01 \\
(0.57-1.80)\end{array}$ \\
\hline $\begin{array}{l}\text { MOENS } \\
{[8]}\end{array}$ & $5(8)$ & $58(92)$ & $20(12)$ & $142(88)$ & & & & $\begin{array}{c}0.61 \\
(0.22-1.71)\end{array}$ \\
\hline $\begin{array}{l}\text { Present } \\
\text { study }\end{array}$ & $7(7)$ & $90(33) \quad 2$ & $211(10)$ & $1899(90)$ & $\longmapsto$ & 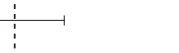 & & $\begin{array}{c}0.70 \\
(0.32-1.53)\end{array}$ \\
\hline $\begin{array}{l}\text { Present } \\
\text { study }^{+}\end{array}$ & $3(7)$ & $40(93)$ & $12(13)$ & $79(87) \longmapsto$ & & & & $\begin{array}{c}0.49 \\
(0.13-1.85)\end{array}$ \\
\hline RE model & $Q=2$ & $2.217(p=0$. & $0.696)$ & & & & & $\begin{array}{c}0.73 \\
(0.51-1.04)\end{array}$ \\
\hline & & & & 0 & 0.5 & $\begin{array}{llll}1 & 1 & 1 & 1 \\
1 & 1.5 & 2 & 2.5\end{array}$ & 4 & \\
\hline
\end{tabular}

b)

\begin{tabular}{|c|c|c|c|c|c|}
\hline \multirow[t]{2}{*}{ Study } & \multicolumn{2}{|c|}{ Patients n (\%) } & \multicolumn{2}{|c|}{ Controls n (\%) } & \multirow{2}{*}{$\begin{array}{c}\text { Observed OR } \\
(95 \% \mathrm{Cl})\end{array}$} \\
\hline & $\mathrm{A} / \mathrm{O}+\mathrm{O} / \mathrm{O}$ & $A / A$ & $A / O+O / O$ & $A / A$ & \\
\hline $\begin{array}{l}\text { Endeman } \\
\text { [22] }\end{array}$ & $22(37)$ & $38(63)$ & $105(47)$ & $118(534) \longmapsto \cdot$ & $\begin{array}{c}0.65 \\
(0.36-1.17)\end{array}$ \\
\hline $\begin{array}{l}\text { Present } \\
\text { study }\end{array}$ & $133(38)$ & 215 (62) & $841(40)$ & $1269(60)$ & $\begin{array}{c}0.93 \\
(0.74-1.18)\end{array}$ \\
\hline $\begin{array}{l}\text { Present } \\
\text { study\# }\end{array}$ & $39(45)$ & $45(54)$ & $36(40)$ & $55(60)$ & $\begin{array}{c}1.32 \\
(0.73-2.41)\end{array}$ \\
\hline \multirow[t]{2}{*}{ RE model } & \multirow{2}{*}{\multicolumn{2}{|c|}{ el $Q=2.753(p=0.0$}} & 0.252) & & $\begin{array}{c}0.93 \\
(0.76-1.14)\end{array}$ \\
\hline & & & & $\begin{array}{llllll}0 & 0.5 & 1 & 1.5 & 2 & 2.5 \\
& & & & & \text { Odds ratio }\end{array}$ & 4 \\
\hline
\end{tabular}

FIGURE 1. Meta-analysis of association between MBL2 and pneumococcal pneumonia. RE: random effects. ${ }^{*}$ : additional group of patients.

b)

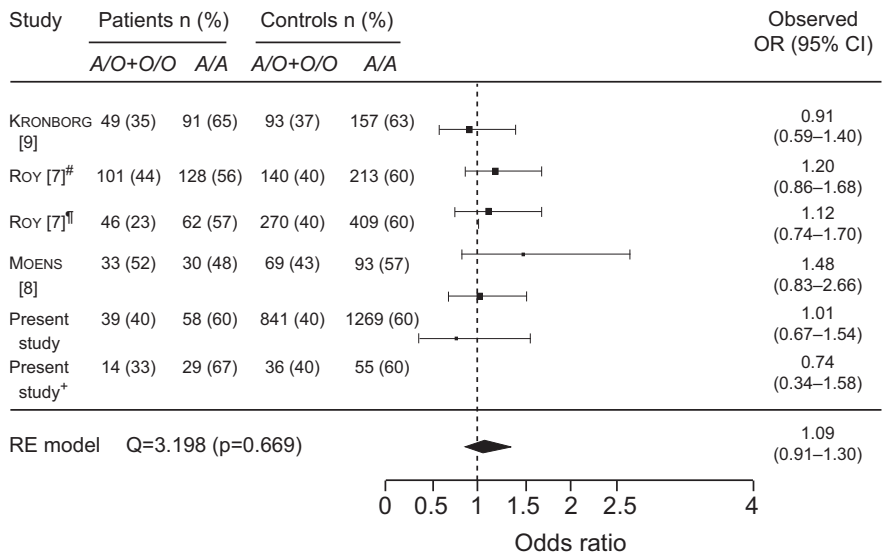

FIGURE 2. Meta-analysis of association between the mannose-binding lectin 2 gene (MBL2) and invasive pneumococcal disease. RE: random-effects. \#: initial group of patients; " group of patients. 


\begin{tabular}{|c|c|c|c|c|c|c|}
\hline \multirow[t]{3}{*}{ TABL } & 5 & \multicolumn{5}{|c|}{$\begin{array}{l}\text { Pairwise linkage disequilibrium measure (D') for } \\
\text { surfactant proteins } A 1, A 2 \text { and } D \text { alleles with } \\
\text { regard to mannose-binding lectin (MBL) alleles } \\
\text { from } 748 \text { healthy controls }\end{array}$} \\
\hline & \multicolumn{6}{|c|}{ MBL2 } \\
\hline & & YB & YC & YD & $X A$ & YA \\
\hline \multicolumn{7}{|c|}{ SFTPA1 } \\
\hline \multicolumn{7}{|l|}{$6 A$} \\
\hline $6 A^{2}$ & 0.53 & $(<0.0001)$ & $0.55(0.033)$ & $0.74(<0.001)$ & $0.31(0.001)$ & \\
\hline $6 A^{3}$ & & $7(0.039)$ & & $0.78(0.006)$ & & \\
\hline $6 A^{4}$ & & $(0.003)$ & & & & \\
\hline \multicolumn{7}{|c|}{ SFTPA2 } \\
\hline $1 A^{0}$ & 0.45 & $(<0.001)$ & $0.71(0.003)$ & $0.76(<0.001)$ & $0.37(<0.001)$ & \\
\hline $1 A^{1}$ & & & $1(0.037)$ & & $0.42(0.026)$ & \\
\hline \multicolumn{7}{|l|}{ SP-D } \\
\hline $\begin{array}{l}\text { Data are } \\
\text { value }> \\
\text { using } A \\
\text { mannos }\end{array}$ & quin ha & $\begin{array}{l}\text { nted as D' } \\
\text { ive not been } \\
3.11 \text { softw } \\
\text { ng lectin } 2 \subseteq\end{array}$ & $\begin{array}{l}\text {-value). D' va } \\
\text { considered. } \\
\text { are. Only rele } \\
\text { yene. }\end{array}$ & $\begin{array}{l}\text { alues }<0.3 \text { or wit } \\
\text { Linkage disequil } \\
\text { evant haplotype }\end{array}$ & $\begin{array}{l}\text { th a correspon } \\
\text { librium was me } \\
\text { are shown. }\end{array}$ & $\begin{array}{l}\text { ig } p- \\
\text { ured } \\
\text { BL2: }\end{array}$ \\
\hline
\end{tabular}

showing that MBL2 genotypes are not involved in susceptibility to either P-CAP or to IPD.

Earlier studies from our group [14] and from ENDEMAN et al. [22] failed to find any significant association between MBL2 genotypes and susceptibility to P-CAP, although both studies were underpowered to test it. When susceptibility to IPD was studied, only one out of three studies found a significant association with the $O / O$ genotype [7-9]. However, a previous meta-analysis of these three studies yielded a significant association [23]. We have now studied the role of MBL2 genotypes on susceptibility to P-CAP and to invasive P-CAP in two different case-control studies, and no association was observed. We also performed a meta-analysis, including the three previous studies [7-9] and our results. Our meta-analysis also showed that $\mathrm{O} / \mathrm{O}$ genotypes significantly associated with susceptibility to IPD. MBL deficiency is considered to result mainly from the presence of $O / O$ or $X A / O$ genotypes $[2,3]$. However, when the genotype $X A / O$ was analysed in our metaanalysis, a surprising trend towards a protective effect against IPD was observed in our meta-analysis. This data is intriguing, as the effect of $O / O$ and $X A / O$ genotypes on MBL levels and MBL-dependent LP activity was repeatedly found to be similar, as it has also been previously reported in our population [2, 14, 24-26]. More recently, a small study in children from Africa suggested that MBL deficiency would associate to IPD by means of low invasive serotypes [27].

MBL deficiency has been associated with infections by Gramnegative bacteria [6]. MBL binding to Pseudomonas aeruginosa has been documented, and susceptibility is conferred by both MBL-deficient genotypes $(O / O$ and $X A / O)$ [28]. However, the proposal of a putative role of MBL deficiency in susceptibility to pneumococcal infection is challenged by several functional and evolutionary studies. The lack of association between MBL deficiency and P-CAP would not be surprising, as no

\begin{tabular}{|c|c|c|c|c|}
\hline \multirow{2}{*}{$\begin{array}{l}\text { TABLE } 6 \\
\text { Haplotype }\end{array}$} & \multicolumn{4}{|c|}{$\begin{array}{l}\text { Comparison of relevant haplotypes } \\
\text { encompassing SFTPD, SFTPA1, SFTPA2 and } \\
\text { MBL2 between pneumococcal community- } \\
\text { acquired pneumonia (P-CAP) patients and } \\
\text { controls }\end{array}$} \\
\hline & P-CAP & Controls & OR (Cl 95\%) & p-value ${ }^{+}$ \\
\hline$X A$ & 48 (16.1) & 388 (21.2) & $0.72(0.51-0.99)$ & 0.053 \\
\hline $6 A^{2}$ & $158(53.0)$ & $1088(59.4)$ & $0.60(0.57-0.99)$ & 0.042 \\
\hline $1 A^{0}$ & $150(50.3)$ & $1069(58.4)$ & $0.72(0.57-0.93)$ & 0.010 \\
\hline $6 A^{2}-X A$ & $23(7.7)$ & 205 (11.2) & $0.66(0.42-1.04)$ & 0.085 \\
\hline $1 A^{0}-X A$ & $21(7.0)$ & 207 (11.3) & $0.60(0.37-0.95)$ & 0.033 \\
\hline $6 A^{2}-1 A^{0}$ & $131(44.0)$ & $940(51.5)$ & $0.74(0.58-0.95)$ & 0.021 \\
\hline $6 A^{2}-1 A^{0}-X A$ & $18(6.0)$ & $185(10.1)$ & $0.57(0.35-0.94)$ & 0.033 \\
\hline$C-6 A^{2}-1 A^{0}-X A$ & $3(1.0)$ & $80(4.4)$ & $0.22(0.07-0.71)$ & 0.005 \\
\hline
\end{tabular}

Data are presented as the $\mathrm{n}$ chromosomes (\%), unless otherwise stated. Only relevant haplotypes are shown. MBL2: mannose-binding lectin 2 gene. ${ }^{\#}: \mathrm{n}=298 ;{ }^{\bullet}: \mathrm{n}=1832{ }^{+}{ }^{*}$ : uncorrected for the bivariate comparison of haplotypes.

MBL binding and/or MBL-mediated opsonophagocytosis of S. pneumoniae was observed in vitro $[10,12]$. The classical pathway of complement is the main complement pathway in host defences against pneumococcus in mice and humans, and loss of the lectin pathway does not seem to affect significantly innate immunity to pneumococcus in mice [11]. Infectious diseases have been the main selective force shaping the human genome during evolution. Pneumonia, particularly by S. pneumoniae, is the biggest killer worldwide of children aged $<5$ yrs [29]. If MBL plays a role in protective immunity against S. pneumoniae, then we would expect a selective removal of MBL2-deficient alleles. However, MBL2-deficient alleles are frequent in many populations worldwide. MBL deficiency was suggested to be protective against several inflammatory and infectious diseases, particularly against tuberculosis, which would positively select for low MBL genotypes. Nevertheless, the results from genetic association studies in the field of tuberculosis are controversial $[6,30]$, and recent studies have shown that the patterns of $M B L 2$ variation worldwide are compatible with neutral evolution $[5,13]$.

The influence of a suspected LD among SFTPA1, SFTPA2 and/ or SFTPD with MBL2 on the results of genetic association studies in infectious diseases has been recently proposed $[6,17]$. We have previously found that several haplotypes of SFTPA1 and SFTPA2 are involved in susceptibility to CAP [17]. When we measured LD among MBL2, SFTPA1, SFTPA2 and SFTPD genes, some SNPs and haplotypes of both SFTPA genes were found to be in LD with $M B L 2$ alleles. Interestingly, an additive effect of the MBL2 $X A$ variant with variants at SFTPA1, SFTPA2 and SFTPD genes on protection against P-CAP was observed. Whether the observed association is due either to epistatic effects or to the existence of an extended protector haplotype encompassing the four genes, or both, is not known. In any event, our results suggest that the trend towards a protective effect of the $M B L 2$ genotype $X A / O$ on susceptibility to P-CAP might be due to LD with protector haplotypes on the genes of the studied SP. Likewise, the reported associations between the MBL2 O/O genotype with 
susceptibility to P-CAP might also be spurious, and due to LD with the SP genes. Wide genetic studies of this region are required to characterise the extent of LD among these genes and its relevance for genetic association studies.

In this and previous studies, $X A / O+O / O$ genotypes and serum MBL-deficiency were associated with a poor prognosis of CAP [14] or pneumococcal disease [25]. Some objections to these results may be argued. How MBL can influence severity of P-CAP if it does not bind to pneumococcus? The rationale for the involvement of MBL deficiency in the severity of pneumonia could be its role in apoptosis [31], or its capacity to bind peptidoglycan and to inhibit peptidoglycan-induced proinflammatory cytokine production by macrophages [32]. However, only a weak statistical significance of MBL genotypes with severity or outcome was observed in our study, which could be even lower if the results were corrected for multiple comparisons. SFTPA1, SFTPA2 and SFTPD variants were found to be involved in severity of CAP [17] and, hence, LD of MBL2 with SP genes could underlie the association of $M B L 2$ deficiency with higher severity and/or poor outcome in CAP and P-CAP. Vaccination against pneumococcus may obviously affect susceptibility to pneumococcal disease, particularly among high-risk individuals. Unfortunately, no data about the vaccination status of most patients against pneumococcus were available. However, pneumococcal vaccine is not included in the Spanish vaccination schedule and most adults have not been vaccinated against pneumococcus.

Overall, our data and several lines of evidence do not support a role of MBL deficiency on susceptibility to P-CAP or to IPD. By contrast, our results suggest that MBL deficiency may be associated with higher severity of P-CAP. However, studies aimed to analyse the role of genetic variability of the MBL gene in infectious diseases, particularly respiratory, should be aware of the existing LD among MBL2 and the genes of SP-A1, -A2 and -D. Identification of new pathways and molecules involved in susceptibility to and severity of respiratory infectious diseases could lead to new therapeutic approaches, and the therapeutic use of MBL and SPs has been advocated [15, 16, 33]. Large studies designed to analyse the genetic variability in the region of chromosome 10 containing these genes are desirable in order to unravel their role in susceptibility and severity of pneumococcal infection, particularly P-CAP.

\section{SUPPORT STATEMENT}

This work was supported by grants from "Fondo de Investigaciones Sanitarias", Ministerio de Sanidad (FIS 02/1620, 04/1190, 06/1031 and 10/01718) with the funding of the European Regional Development Fund-European Social Fund (FEDER-FSE), RedRespira-ISCIII-RTIC03/11, Sociedad Española de Neumología y Cirugía Torácica' (SEPAR) FUNCIS, Gobierno de Canarias (04/09 and INREDCAN 5/06); M.I. García-Laorden was supported by FUNCIS (Proyecto Bioregion 2006) and E. Herrera-Ramos by a grant from Universidad de Las Palmas de Gran Canaria.

\section{STATEMENT OF INTEREST}

None declared.

\section{ACKNOWLEDGEMENTS}

The authors' affiliations are: M.I. García-Laorden, Dept of Immunology, Hospital Universitario de Gran Canaria Dr Negrín, Las Palmas de Gran Canaria, Spain; F. Rodríguez de Castro, Dept of Respiratory
Diseases, Hospital Universitario de Gran Canaria Dr Negrín, and Dept of Medical and Surgical Sciences, School of Medicine, University of Las Palmas de Gran Canaria, Las Palmas de Gran Canaria; J. Solé-Violán, Intensive Care Unit, Hospital Universitario de Gran Canaria Dr Negrín; A. Payeras, Dept of Internal Medicine, Hospital Son Llatzer, Palma de Mallorca, Spain; M.L. Briones, Dept of Respiratory Diseases, Hospital Clínica y Universitario de Valencia, Valencia, Spain; L. Borderíal, Dept of Respiratory Diseases, Hospital San Jorge, Huesca, Spain; J. Aspa, Dept of Respiratory Diseases, Hospital Universitario de la Princesa, Madrid, Spain; J. Blanquer, Intensive Care Unit, Hospital Clínico y Universitario de Valencia; O. Rajas, Dept of Respiratory Diseases, Hospital Universitario de la Princesa; J.A. Marcos-Ramos, Intensive Care Unit, Hospital Dr José Molina Orosa, Lanzarote, Spain; E. Herrera-Ramos, Dept of Immunology, Hospital Universitario de Gran Canaria Dr Negrín; M.A. García-Bello, Research Unit, Hospital Universitario de Gran Canaria Dr Negrín; J. Noda, Dept of Immunology, Hospital Universitario de Gran Canaria Dr Negrín; J.M. Ferrer, Intensive Care Unit, Hospital Universitario de Gran Canaria Dr Negrín; J. Rello, Hospital Vall d'Hebron, Universitat Autonoma de Barcelona, CIBERES, Institut de Recerca Vall d'Hebron (VHIR). Barcelona, Spain; and C. Rodríguez-Gallego, Dept of Immunology, Hospital Universitario de Gran Canaria Dr Negrín and Dept of Medical and Surgical Sciences, School of Medicine, University of Las Palmas de Gran Canaria.

We are grateful to the patients and their families for their trust, as well as to the healthy volunteers. We also thank A.R. Domínguez-Acosta, N. González-Quevedo, Y. Florido (Dept of Immunology, Hospital Universitario de Gran Canaria Doctor Negrín), C. Ivañez (Dept of Respiratory Diseases, Hospital Universitario de Gran Canaria Doctor Negrín) and I. Martin-Loeches (Dept of Intensive Care Unit, Complejo Hospitalario Parc-Taulí) for their invaluable help, and P. Mangiaracina (Peter's Language Services, Las Palmas de Gran Canaria, Spain) for his assistance with the final editing of the English manuscript.

\section{REFERENCES}

1 Mandell LA, Wunderink RG, Anzueto A, et al. Infectious Diseases Society of America/American Thoracic Society consensus guidelines on the management of community-acquired pneumonia in adults. Clin Infect Dis 2007; 44: Suppl. 2, S27-S72.

2 Dommett RM, Klein N, Turner MW. Mannose-binding lectin in innate immunity: past, present and future. Tissue Antigens 2006; 68: 193-209.

3 García-Laorden MI, Manzanedo A, Figuerola A, et al. Mannosebinding lectin polymorphisms in a Canary Islands (Spain) population. Genes Immun 2001; 2: 292-294.

4 Geha RS, Notarangelo LD, Casanova JL, et al. Primary immunodeficiency diseases: an update from the International Union of Immunological Societies Primary Immunodeficiency Diseases Classification Committee. J Allergy Clin Immunol 2007; 120: 776-794.

5 Verdu P, Barreiro LB, Patin E, et al. Evolutionary insights into the high worldwide prevalence of MBL2 deficiency alleles. Hum Mol Genet 2006; 15: 2650-2658.

6 Eisen DP. Mannose-binding lectin deficiency and respiratory tract infection. J Innate Immun 2010; 2: 114-122.

7 Roy S, Knox K, Segal S, et al. Oxford Pneumoccocal Surveillance Group. MBL genotype and risk of invasive pneumococcal disease: a case-control study. Lancet 2002; 359: 1569-1573.

8 Moens L, Van Hoeyveld E, Peetermans WE, et al. Mannosebinding lectin genotype and invasive pneumococcal infection. Hum Immunol 2006; 67: 605-611.

9 Kronborg G, Weis N, Madsen HO, et al. Variant mannose-binding lectin alleles are not associated with susceptibility to or outcome of invasive pneumococcal infection in randomly included patients. J Infect Dis 2002; 185: 1517-1520. 
10 Neth O, Jack DL, Dodds AW, et al. Mannose-binding lectin binds to a range of clinically relevant microorganisms and promotes complement deposition. Infect Immun 2000; 68: 688-693.

11 Brown JS, Hussell T, Gilliland SM, et al. The classical pathway is the dominant complement pathway required for innate immunity to Streptococcus pneumoniae infection in mice. Proc Natl Acad Sci USA 2002; 99: 16969-16974.

12 Brouwer N, Dolman KM, van Houdt M, et al. Mannose-binding lectin (MBL) facilitates opsonophagocytosis of yeasts but not of bacteria despite MBL binding. J Immunol 2008; 180: 4124-4132.

13 Boldt $\mathrm{AB}$, Messias-Reason IJ, Meyer D, et al. Phylogenetic nomenclature and evolution of mannose-binding lectin (MBL2) haplotypes. BMC Genet 2010; 11: 38.

14 Garcia-Laorden MI, Sole-Violan J, Rodriguez de Castro F, et al. Mannose-binding lectin and mannose-binding lectin-associated serine protease 2 in susceptibility, severity, and outcome of pneumonia in adults. J Allergy Clin Immunol 2008; 122: 368-374.

15 Haczku A. Protective role of the lung collectins surfactant protein A and surfactant protein D in airway inflammation. J Allergy Clin Immunol 2008; 122: 861-879.

16 Wright JR. Immunoregulatory functions of surfactant proteins. Nat Rev Immunol 2005; 5: 58-68.

17 García-Laorden MI, Rodríguez de Castro F, Solé-Violán J, et al. Influence of genetic variability at the surfactant proteins $\mathrm{A}$ and $\mathrm{D}$ in community-acquired pneumonia: a prospective, observational, genetic study. Crit Care 2011; 15: R57.

18 Hoover RR, Floros J. Organization of the human SP-A and SP-D loci at 10q22-q23. Physical and radiation hybrid mapping reveal gene order and orientation. Am J Respir Cell Mol Biol 1998; 18: 353-362.

19 Perez-Castellano M, Peñaranda M, Payeras A, et al. Mannosebinding lectin does not act as an acute-phase reactant in adults with community-acquired pneumococcal pneumonia. Clin Exp Immunol 2006; 145: 228-234.

20 García-Laorden MI, Rúa-Figueroa I, Pérez-Aciego $\mathrm{P}$, et al. Mannose binding lectin polymorphisms as a disease-modulating factor in women with systemic lupus erythematosus from Canary Islands, Spain. J Rheumatol 2003; 30: 740-746.

21 DiAngelo S, Lin Z, Wang G, et al. Novel., non-radioactive, simple and multiplex PCR-Crflp methods for genotyping human SP-A and SP-D marker alleles. Dis Markers 1999; 15: 269-281.
22 Endeman H, Herpers BL, de Jong BA, et al. Mannose-binding lectin genotypes in susceptibility to community-acquired pneumonia. Chest 2008; 134: 1135-1140.

23 Brouwer MC, de Gans J, Heckenberg SG, et al. Host genetic susceptibility to pneumococcal and meningococcal disease: a systematic review and meta-analysis. Lancet Infect Dis 2009; 9: $31-44$.

24 Garcia-Laorden MI, Pena MJ, Caminero JA, et al. Influence of mannose-binding lectin on HIV infection and tuberculosis in a Western-European population. Mol Immunol 2006; 43: 2143-2150.

25 Eisen DP, Dean MM, Boermeester MA, et al. Low serum mannosebinding lectin level increases the risk of death due to pneumococcal infection. Clin Infect Dis 2008; 47: 510-516.

26 Swierzko AS, Szala A, Cedzynski M, et al. Mannan-binding lectin genotypes and genotype-phenotype relationships in a large cohort of Polish neonates. Hum Immunol 2009; 70: 68-72.

27 Vallès X, Roca A, Lozano F, et al. Serotype-specific pneumococcal disease may be influenced by mannose-binding lectin deficiency. Eur Respir J 2010; 36: 856-863.

28 Chalmers JD, Fleming GB, Hill AT, et al. Impact of mannosebinding lectin insufficiency on the course of cystic fibrosis: a review and meta-analysis. Glycobiology 2011; 21: 271-282.

29 O'Brien KL, Wolfson LJ, Watt JP, et al. Burden of disease caused by Streptococcus pneumoniae in children younger than 5 years: global estimates. Lancet 2009; 374: 893-902.

30 Denholm JT, McBryde ES, Eisen DP. Mannose-binding lectin and susceptibility to tuberculosis: a meta-analysis. Clin Exp Immunol 2010; 162: 84-90.

31 Stuart LM, Takahashi K, Shi L, et al. Mannose-binding lectindeficient mice display defective apoptotic cell clearance but no autoimmune phenotype. J Immunol 2005; 174: 3220-3226.

32 Nadesalingam J, Dodds AW, Reid KBM, et al. Mannose-binding lectin recognizes peptidoglycan via the $N$-acetyl glucosamine moiety, and inhibits ligand-induced proinflammatory effect and promotes chemokine production by macrophages. J Immunol 2005; 175: 1785-1794.

33 Bang $\mathrm{P}$, Laursen I, Thornberg K, et al. The pharmacokinetic profile of plasma-derived mannan-binding lectin in healthy adult volunteers and patients with Staphylococcus aureus septicaemia. Scand J Infect Dis 2008; 40: 44-48. 